\title{
Effects of Number of Graphite Nodules on Fatigue Limit and Fracture Origins in Heavy Section Spheroidal Graphite Cast Iron*1
}

\author{
Naoto Shiraki ${ }^{1}$, Yuki Usui ${ }^{1, * 2}$ and Toshitake Kanno ${ }^{2}$ \\ ${ }^{1}$ Faculty of Engineering, Tokyo City University, Tokyo 158-8557, Japan \\ ${ }^{2}$ Kimura Chuzosho Co., LTD., Omaezaki 437-1615, Japan
}

\begin{abstract}
The purpose of this study is to investigate the effects of number of graphite nodules on fatigue limit and fracture origins in spheroidal graphite cast iron where carbon content and the number of graphite nodules are changed. As specimens, spheroidal graphite cast irons with 3.0, 3.2, 3.4, 3.6 and 3.8 mass\% carbon content were produced respectively. Matrix was conducted pearlite (PDI) and ausferrite (ADI) by heat treatment (normalizing and austempering). The mean diameter of the graphite nodule decreases as the carbon content increases, and the number of graphite nodules per unit area increases. No differences were observed in tensile strength as a result of variations in the number of graphite nodules. The rotating bending fatigue test was conformed to JIS (Japanese Industrial Standards). Load frequency was $47 \mathrm{rpm}$, number of cycle to discontinue test was $1.0 \times 10^{7}$ cycles, and the specimen used was the 1 type of $8.00 \mathrm{~mm}$ in diameter. All the fracture surfaces were observed with a scanning electron microscope. The relationship between the characteristics of fatigue strength and the size of fracture origins (defect size) was investigated.

No differences were observed in fatigue limit as a result of variations in the number of graphite nodules. Fracture origins were microshrinkage, unspheroidizing graphite nodule and aggregate graphite nodules. The percentage of fracture origin of aggregate graphite nodules was increased by cluster of the graphite nodules. The reason of this phenomenon was due to the decrease of the graphite nodules spacing. The mean defect size in each sample was constant irrespective of the change of number of graphite nodules, which was good agreement with the results of the fatigue limit. [doi:10.2320/matertrans.F-M2015841]
\end{abstract}

(Received August 24, 2015; Accepted November 27, 2015; Published February 25, 2016)

Keywords: number of graphite nodules, fatigue limit, fracture origin, spheroidal graphite cast iron, rotating bending fatigue test, defect size

\section{Introduction}

Spheroidal graphite cast iron, which exhibits strength and toughness comparable to steel, with excellent characteristics such as casting and cutting performance and low melting point, is widely used as a substitute for steel in machine parts for general and electric machinery and transportation machinery. However, fatigue fracture should be taken into account in the design of such machine parts, to which load is applied repeatedly. On the other hand, the microstructure of spheroidal graphite cast iron contains a large number of graphite nodules of which the Young's modulus and the strength are remarkably smaller than those of the matrix whereby the graphite nodules in the matrix can be regarded as micro-defects. ${ }^{1)}$ The defect size is larger than that of steel and, because the defects can become the origin for fatigue fracture, the fatigue strength is inferior to that of the steel with the same hardness. ${ }^{2}$ Furthermore, the spheroidal graphite cast iron is evaluated only through static strength in the Japanese Industrial Standards, and the chemical compositions are not specifically prescribed as done in the carbon steel for machine parts. In fact, it is reported that, in the spheroidal graphite cast iron, the diameter of spheroidal graphite and the number of graphite depend on the carbon content; the diameter of spheroidal graphite increases and the number of graphite decreases as the carbon content decreases while the diameter of spheroidal graphite decreases and the number of graphite increases as the carbon content increases. ${ }^{3)}$ If the graphite nodule is spherical, the stress concentration acting on the graphite nodule edge should not

\footnotetext{
${ }^{* 1}$ This Paper was Originally Published in Japanese in J. JFS 86 (2014) 615 620 .

${ }^{* 2}$ Graduate Student, Tokyo City University
}

depend on the diameter of spheroidal graphite and is dynamically identical. However, if the number of graphite increases, the graphite nodule spacing becomes small and accordingly the graphite nodule group could act as a single defect; as a result, the number of graphite can affect the fatigue strength characteristics.

In recent years, for substance of spheroidal graphite cast iron, the importance of the quality assurance by means of non-destructive testing is pointed out. ${ }^{4)}$ Ultrasound studies can reveal the mechanical properties such as the ratio of graphite spheroidization and the hardness and also estimate the location and the size of the micro shrinkage. Furthermore, using these techniques, it is attempted to evaluate the harmful effects of defects on the casting products. ${ }^{5)}$ However, there are almost no reports on the kind and the size of the origin of fatigue fracture in spheroidal graphite cast iron, and it is necessary to understand the kind and the size of defects that can act as the fracture origin of fatigue fractures observed in the destructive test in order to help develop nondestructive defect assessment methodologies using ultrasound and other techniques.

Therefore by considering the kind and the size of the fracture origins of fatigue fracture, we performed rotating bending fatigue tests of spheroidal graphite cast iron with different matrices obtained by controlling the carbon content to change the number of graphite and specifically examined the influence of the number of graphite on the fatigue strength.

\section{Sample Materials}

After the control of the carbon content, specimens are poured to obtain ten kinds of spheroidal graphite cast iron with different matrices. The content of $\mathrm{Si}$ is controlled to 
Table 1 Chemical composition of material used; (a) PDI, (b) ADI.

(a)

\begin{tabular}{ccccccc}
\hline Material & $\mathrm{C}$ & $\mathrm{Si}$ & $\mathrm{Mn}$ & $\mathrm{P}$ & $\mathrm{Mg}$ & $\mathrm{S}$ \\
\hline PDI3.0 & 3.04 & 2.36 & 0.25 & 0.013 & 0.053 & 0.006 \\
PDI3.2 & 3.23 & 2.35 & 0.25 & 0.012 & 0.054 & 0.005 \\
PDI3.4 & 3.43 & 2.36 & 0.26 & 0.013 & 0.055 & 0.004 \\
PDI3.6 & 3.63 & 2.37 & 0.26 & 0.013 & 0.054 & 0.005 \\
PDI3.8 & 3.77 & 2.36 & 0.26 & 0.013 & 0.058 & 0.004 \\
\hline
\end{tabular}

(b)

\begin{tabular}{ccccccc}
\hline Material & $\mathrm{C}$ & $\mathrm{Si}$ & $\mathrm{Mn}$ & $\mathrm{P}$ & $\mathrm{Mg}$ & $\mathrm{S}$ \\
\hline ADI3.0 & 3.02 & 2.42 & 0.25 & 0.013 & 0.054 & 0.004 \\
ADI3.2 & 3.22 & 2.38 & 0.25 & 0.013 & 0.053 & 0.004 \\
ADI3.4 & 3.40 & 2.37 & 0.25 & 0.014 & 0.057 & 0.006 \\
ADI3.6 & 3.63 & 2.39 & 0.23 & 0.013 & 0.054 & 0.005 \\
ADI3.8 & 3.74 & 2.40 & 0.24 & 0.016 & 0.055 & 0.005 \\
\hline
\end{tabular}

approximately 2.4 mass $\%$ while the carbon content is controlled to approximately 3.0, 3.2, 3.4, 3.6 and 3.8 mass $\%$, respectively. ${ }^{3)}$ Table 1(a),(b) show the chemical compositions of pearlite spheroidal graphite cast iron (PDI) and austempered spheroidal graphite cast iron (ADI). The chemical compositions of these two kinds of material are approximately equal. In the following, the name of the test material (for example, ADI3.0) shows the combination of both matrix type and carbon content. In casting the test specimens, the mold with w400 $\mathrm{mm} \times \mathrm{t} 600 \mathrm{~mm} \times \mathrm{h} 300 \mathrm{~mm}$ was used; the molten metal $54 \mathrm{~kg}$ was melted in an electric furnace and poured into the upper open end of the mold with the tapping temperature $1773 \mathrm{~K}$ and the pouring temperature $1623 \mathrm{~K}$ to make an ingot of $\mathrm{w} 230 \mathrm{~mm} \times \mathrm{t} 190 \mathrm{~mm} \times \mathrm{h} 170 \mathrm{~mm}$. After cutting and removing the lower portion $10 \mathrm{~mm}$ of the ingot, the $60 \mathrm{~mm}$ portion above the cutting plane was cut out and formed into round bars of diameter $18 \mathrm{~mm}$, which are then heat-treated. The PDI material went through a pearlitizing normalization process in the air at $1203 \mathrm{~K}$ for $18 \mathrm{ks}$, while the ADI material was kept in the air at $1173 \mathrm{~K}$ for $3.6 \mathrm{ks}$ and then went through an austempering process: isothermal transformation in a salt-bath furnace at $648 \mathrm{~K}$ for $3.6 \mathrm{ks}$ followed by air cooling.

Figures 1(a), (b) show the photograph of the microstructure, the ratio of graphite spheroidization, the mean diameter of spheroidal graphite, the number of graphite per unit area and the graphite nodule spacing of the material specimens. The ratio of graphite spheroidization was evaluated based on JIS G 5502: spheroidal graphite iron castings. ${ }^{6}$ In addition, the mean diameter of spheroidal graphite for each specimen was obtained by measuring and averaging the diameters of graphite nodules in the 5 fields of vision at magnification of 200 times with an optical microscope. The number of graphite per unit area was obtained by measuring and averaging the number of graphite in $1 \mathrm{~mm}^{2}$ at five places per specimen at magnification of 200 times with an optical microscope. The graphite nodule spacing was obtained for each material by measuring and (a)

\begin{tabular}{|c|c|c|c|c|c|}
\hline & PDI 3.0 & PDI 3.2 & PDI 3.4 & PDI 3.6 & PDI 3.8 \\
\hline $\begin{array}{l}\text { Microstructure } \\
\qquad 300 \mu \mathrm{m}\end{array}$ & $80^{2}-3$ & 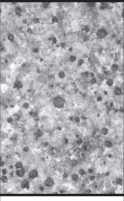 & 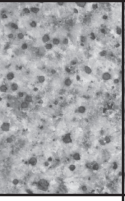 & $\begin{array}{c}1 \\
6 \\
0 \\
0\end{array}$ & 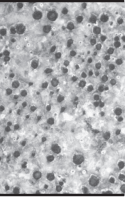 \\
\hline $\begin{array}{l}\text { Ratio of graphite } \\
\text { spheroidization } / \%\end{array}$ & 92 & 93 & 90 & 93 & 93 \\
\hline $\begin{array}{c}\text { Mean diameter of } \\
\text { graphite nodule / } \mu \mathrm{m}\end{array}$ & 41 & 37 & 36 & 31 & 32 \\
\hline $\begin{array}{c}\text { Number of graphite nodules } \\
\text { in microstructure } / / \mathrm{mm}^{2}\end{array}$ & 56 & 67 & 71 & 103 & 113 \\
\hline $\begin{array}{c}\text { Mean graphite } \\
\text { nodules spacing / } \mu \mathrm{m}\end{array}$ & 46 & 44 & 39 & 31 & 28 \\
\hline
\end{tabular}

(b)

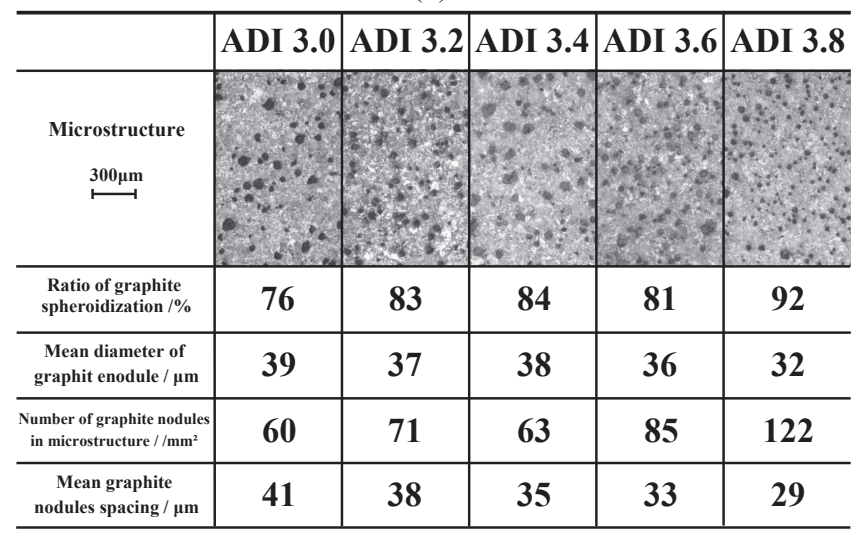

Fig. 1 Microstructure and graphite state at each material; (a) PDI, (b) ADI.

averaging the nearest neighbor distance for greater than 400 graphite nodules. The PDI matrix had an approximately uniform perlite structure, while the ADI matrix had an ausferritic structure containing a small amount of retained austenite. The ratios of graphite spheroidization in the materials are greater than $80 \%$ approximately except ADI3.0 of which the ratio is less than $80 \%$. As the carbon content increases, the mean diameter of spheroidal graphite and the mean graphite nodule spacing decrease nearly monotonically while the number of graphite per unit area increases.

Table 2(a),(b) show the mechanical properties and Vickers hardness of the matrices. Thereby, three specimens were used in the tensile tests for each material. The dependence of tensile strength and percentage elongation was not seen on the number of graphite in the matrix. Note that, though the ADI3.0 material having the spheroidization ratio of less than $80 \%$ as discussed earlier is not precisely classifiable as spheroidal graphite cast iron, ${ }^{6}$ it was decided to view such material as spheroidal graphite cast iron because no differences were seen in the mechanical properties compared with other ADI materials.

\section{Experimental Procedure}

The rotating bending fatigue test was performed using an Ono-type rotating bending fatigue testing machine with $98 \mathrm{~N}$ $\mathrm{m}$ capacity. The loading frequency was $47 \mathrm{rpm}$, the test was performed in the air at room temperature, and the number of 
Table 2 Mechanical properties of spheroidal graphite cast iron in each material; (a) PDI, (b) ADI.

(a)

\begin{tabular}{|c|c|c|c|c|c|c|c|}
\hline & $\begin{array}{c}0.2 \% \text { Proof } \\
\text { stress } \\
\sigma_{0.2} / \mathrm{MPa}\end{array}$ & $\begin{array}{l}\text { Tensile } \\
\text { strength } \\
\sigma_{\mathrm{B}} / \mathrm{MPa}\end{array}$ & $\begin{array}{c}\text { Elongation } \\
\delta / \%\end{array}$ & $\begin{array}{c}\text { Reduction } \\
\text { of area } \\
\varphi / \% \\
\end{array}$ & $\begin{array}{c}\text { Young's } \\
\text { modulus } \\
E / \mathrm{GPa}\end{array}$ & $\begin{array}{c}\text { Vickers } \\
\text { hardness } \\
H V_{0.05}\end{array}$ & $\begin{array}{c}\text { Fatigue } \\
\text { limit } \\
\sigma_{\mathrm{w}} / \mathrm{MPa}\end{array}$ \\
\hline PDI3.0 & 678 & 1048 & 5 & 4 & 172 & 354 & 275 \\
\hline PDI3.2 & 683 & 1051 & 5 & 5 & 177 & 354 & 315 \\
\hline PDI3.4 & 663 & 1039 & 5 & 4 & 175 & 358 & 315 \\
\hline PDI3.6 & 663 & 1022 & 5 & 4 & 171 & 352 & 295 \\
\hline PDI3.8 & 662 & 1010 & 5 & 4 & 170 & 353 & 310 \\
\hline
\end{tabular}

(b)

\begin{tabular}{|c|c|c|c|c|c|c|c|}
\hline & $\begin{array}{c}0.2 \% \text { Proof } \\
\text { stress } \\
\sigma_{0.2} / \mathrm{MPa}\end{array}$ & $\begin{array}{c}\text { Tensile } \\
\text { strength } \\
\sigma_{\mathrm{B}} / \mathrm{MPa}\end{array}$ & $\begin{array}{c}\text { Elongation } \\
\delta / \%\end{array}$ & $\begin{array}{c}\text { Reduction } \\
\text { of area } \\
\varphi / \%\end{array}$ & $\begin{array}{l}\text { Young's } \\
\text { modulus } \\
E / \mathrm{GPa}\end{array}$ & $\begin{array}{c}\text { Vickers } \\
\text { hardness } \\
H V_{0.05}\end{array}$ & $\begin{array}{c}\text { Fatigue } \\
\text { limit } \\
\sigma_{\mathrm{w}} / \mathrm{MPa}\end{array}$ \\
\hline ADI3.0 & 853 & 1052 & 6 & 6 & 161 & 426 & 345 \\
\hline ADI3.2 & 835 & 1009 & 5 & 6 & 160 & 419 & 345 \\
\hline ADI3.4 & 820 & 1031 & 5 & 6 & 159 & 426 & 345 \\
\hline ADI3.6 & 840 & 1028 & 5 & 6 & 159 & 433 & 355 \\
\hline
\end{tabular}

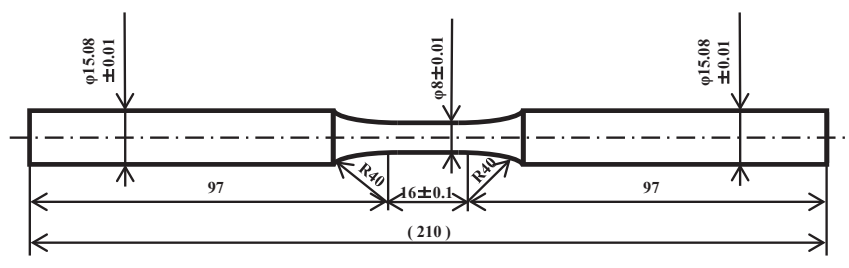

Fig. 2 Shape and dimension of specimen in rotating bending fatigue test.

repetitions before the termination of the test was $1 \times 10^{7}$ times; the test specimens reaching the test termination cycle were fractured by applying an excess load of 20-30 MPa relative to the fatigue limit. The test specimens are No. 1 rotating bending fatigue test specimens in conformity with JIS Z 2274 with the diameter of $8 \mathrm{~mm}$ in the parallel portion. ${ }^{7)}$ Figure 2 shows the shape and the dimensions of the test specimen. The parallel portion of the specimen was polished with emery paper up to \#2000 and then mirrorfinished with an $\mathrm{Al}_{2} \mathrm{O}_{3}$ abrasive of mean particle size $0.25 \mu \mathrm{m}$. Further, the number of specimens was 15-16 for each material and the test was performed until at least three or more of them reached the test termination cycle. The approximating method of the S-N diagram obtained by the rotating bending fatigue test is based on JSMS-SD-6-04. ${ }^{8}$ After the rotating bending fatigue test, the fractured surface of the specimen was observed around the fracture origins using scanning electron microscopy.

\section{Experimental Results and Discussion}

Table 2 also shows the fatigue limit of each material evaluated by the rotating bending fatigue test. Further, Fig. 3 shows the relationship between the fatigue limit and the number of graphite. The difference of the fatigue limit on the number of graphite was not seen in the ADI materials. In the

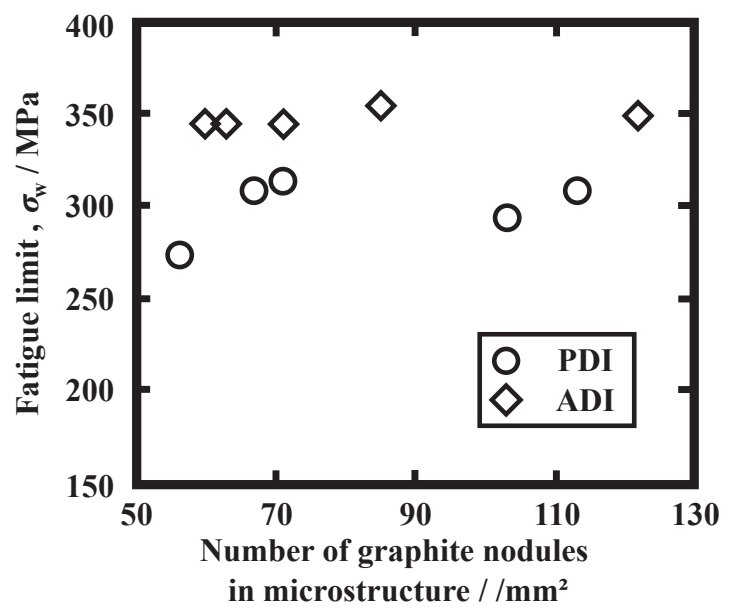

Fig. 3 Relationship between fatigue limit and number of graphite nodules in microstructure.

PDI3.0 material, though the results of the $0.2 \%$ proof stress and the tensile strength were the same with those of the other PDI materials, the decrease of fatigue limit was confirmed. However, the reason could not be clarified even by the results of the fracture observation as discussed later.

Figure 4 shows the example photos of fracture origins in PDI materials. The secondary electron images and composition images are also shown in Fig. 4 in order to clearly distinguish between starting points. It is shown that the fracture origins are classified roughly into three kinds: micro shrinkage, unspheroidizing graphite nodules, and aggregate graphite nodules. The aggregate graphite nodules are a graphite nodule group acting as a single fracture origin. Figure 5 shows the percentage of the three kinds of fracture origins in each material evaluated by observing the fractured surface of all specimens. Micro shrinkage and unspheroidizing graphite nodules served as fracture origins in the 
specimens with a small carbon content and a small number of graphite, while aggregate graphite nodules accounted for a larger percentage of fracture origins in the specimens with a large carbon content and a large number of graphite. It is considered that this occurs because the graphite nodule spacing decreases as the number of graphite increases. Therefore Fig. 6 shows the relationship between the mean graphite nodule spacing and the percentage of specimens in which the aggregate graphite nodules became the fracture origin. From the fact that the percentage of specimens in which aggregate graphite nodules became fracture origins

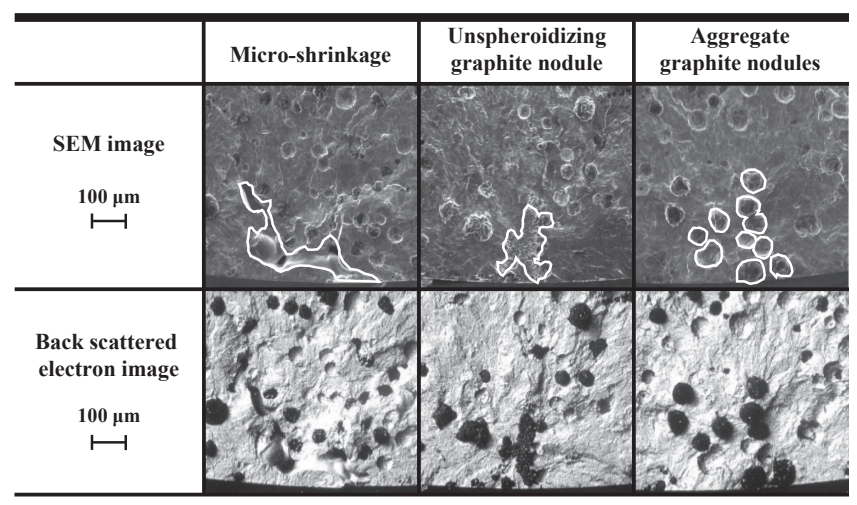

Fig. 4 Examples of fracture origins observed by SEM. increased as the mean graphite nodule spacing decreased, it is reasonable to assume that the graphite nodule group acts as a single defect when the mean graphite nodule spacing becomes small. In addition, Table 3 shows the measured results of the graphite nodule spacing for the cases that graphite nodule groups became fracture origins. When we pay attention to the maximum graphite nodule spacing, it is $48.6 \mu \mathrm{m}$ in PDI materials and $44.1 \mu \mathrm{m}$ in ADI materials, suggesting that graphite nodules with spacing smaller than these values could become aggregate graphite nodules. Therefore, among the graphite nodules in the microstructure in which graphite nodule spacing was measured, Fig. 7 shows the relationship between the percentage of graphite nodules with spacing of $48.6 \mu \mathrm{m}$ or less in the PDI materials and $44.1 \mu \mathrm{m}$ or less in the ADI materials and the carbon content. It is clearly indicated that, both in ADI and PDI materials, the percentage of graphite nodules having the graphite nodule spacing that could act as fracture origins of

Table 3 Graphite nodules spacing at aggregate graphite nodules.

\begin{tabular}{ccc}
\hline & PDI & ADI \\
\hline Average $/ \mu \mathrm{m}$ & 14.6 & 15.8 \\
Maximum $/ \mu \mathrm{m}$ & 48.6 & 44.1 \\
Minimum $/ \mu \mathrm{m}$ & 2.7 & 2.2 \\
\hline
\end{tabular}
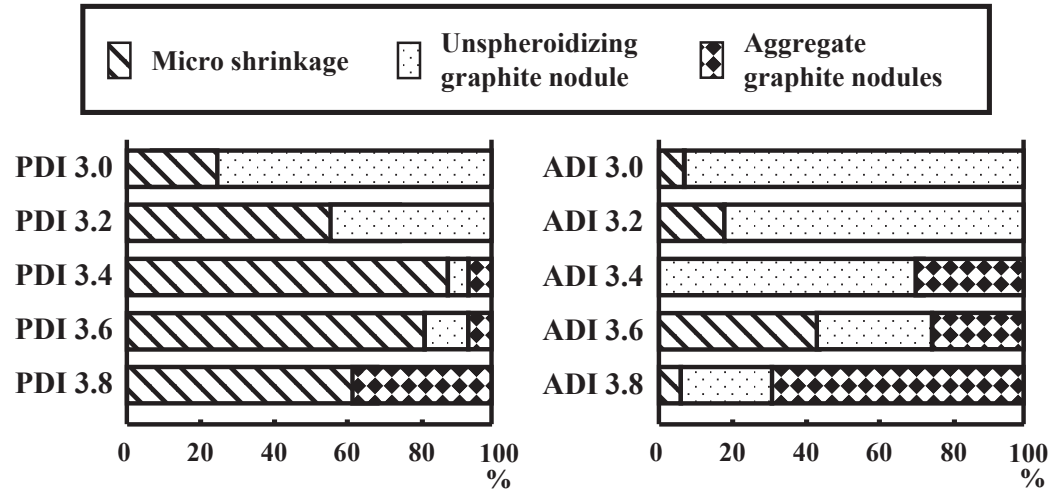

Fig. 5 Percentage of three kinds of fracture origins in each material.

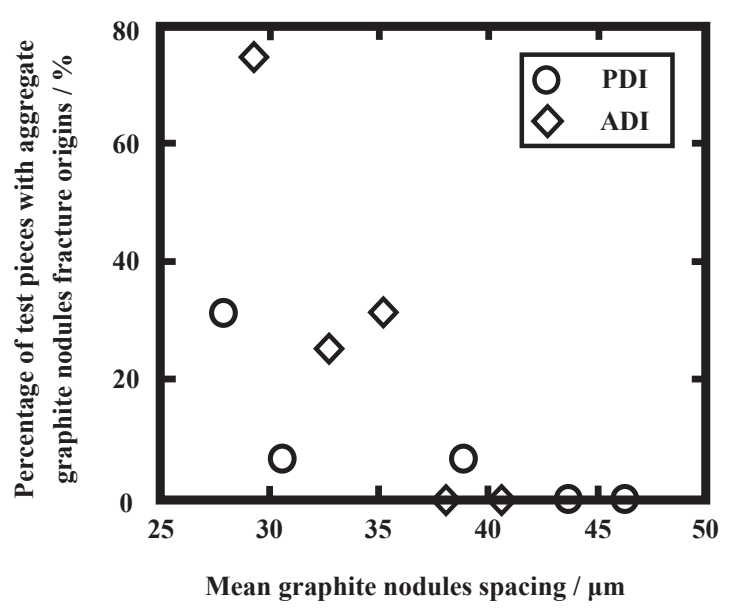

Fig. 6 Relationship between percentage of test pieces with aggregate graphite nodules fracture origins and mean graphite nodules spacing.

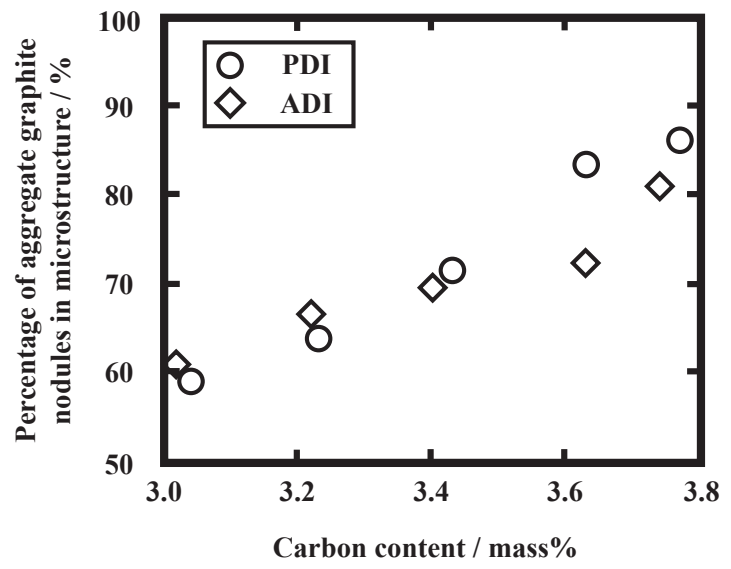

Fig. 7 Relationship between percentage of aggregate graphite nodules in microstructure and carbon content. 


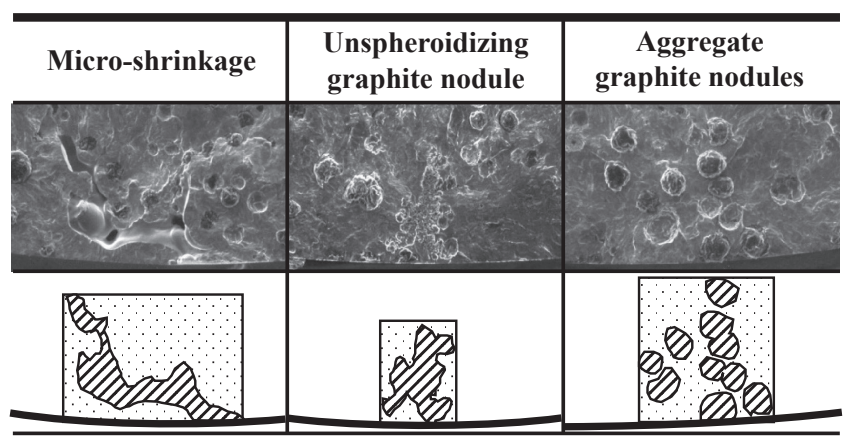

Fig. 8 SEM image and approximate rectangle area at fracture origins.

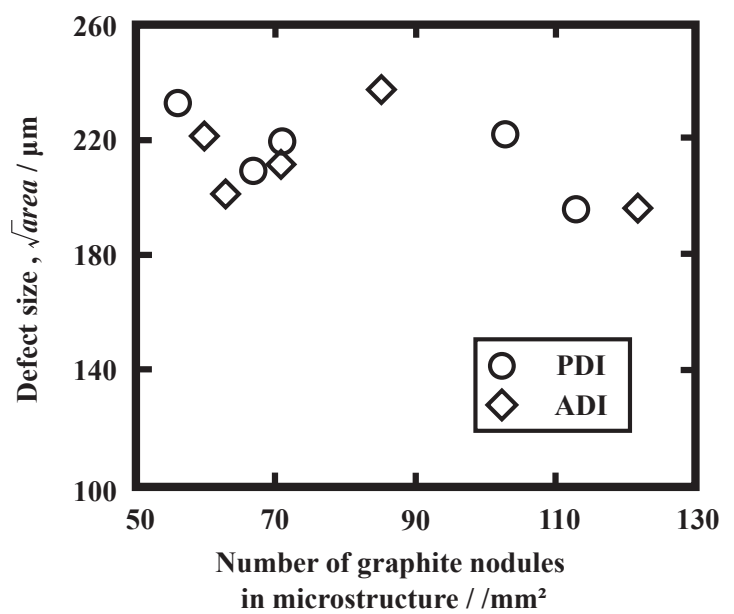

Fig. 9 Relationship between defect size and number of graphite nodules.

aggregate graphite nodules increases as the carbon content increases; in the ADI3.8, PDI3.6 and PDI3.8 materials, the graphite nodules are found very close to each other and accordingly more than $80 \%$ of graphite nodules could become aggregate graphite nodules.

It is known that, in the defect size measurement, the defect is regarded as a small crack (not as a notch) and the developmental state of a crack starting from a small defect is dynamically equivalent to that of a crack having an area projected to the same maximum main stress direction. Therefore, $\sqrt{\text { area }}$ would be a good representative dimension applicable to any complicatedly shaped defect in a unified manner. ${ }^{9)}$ In this regard, the size of the defect that became the starting point of fatigue fracture was evaluated. In obtaining the defect size, the fracture origins of the fractured specimens were approximated by rectangles regardless of the type of fracture origins as shown in Fig. 8, and the square root of the area, $\sqrt{\text { area }}$, was defined as the defect size. The defect sizes of the measured specimens were plotted on gumbel paper, and the defect size corresponding to the value of the cumulative distribution function $F=50 \%, \sqrt{\text { area }}_{F=50 \%}$, was defined as the mean defect size. And Fig. 9 shows the relationship between the mean defect size and the number of graphite for all fracture origins for the two types of materials. In addition, it is expected that the defect size would depend on the specimen cutting position, but actually the influence of defect size, kind, and specimen cutting position was not found. Since the three kinds of defects as shown in Fig. 8 are
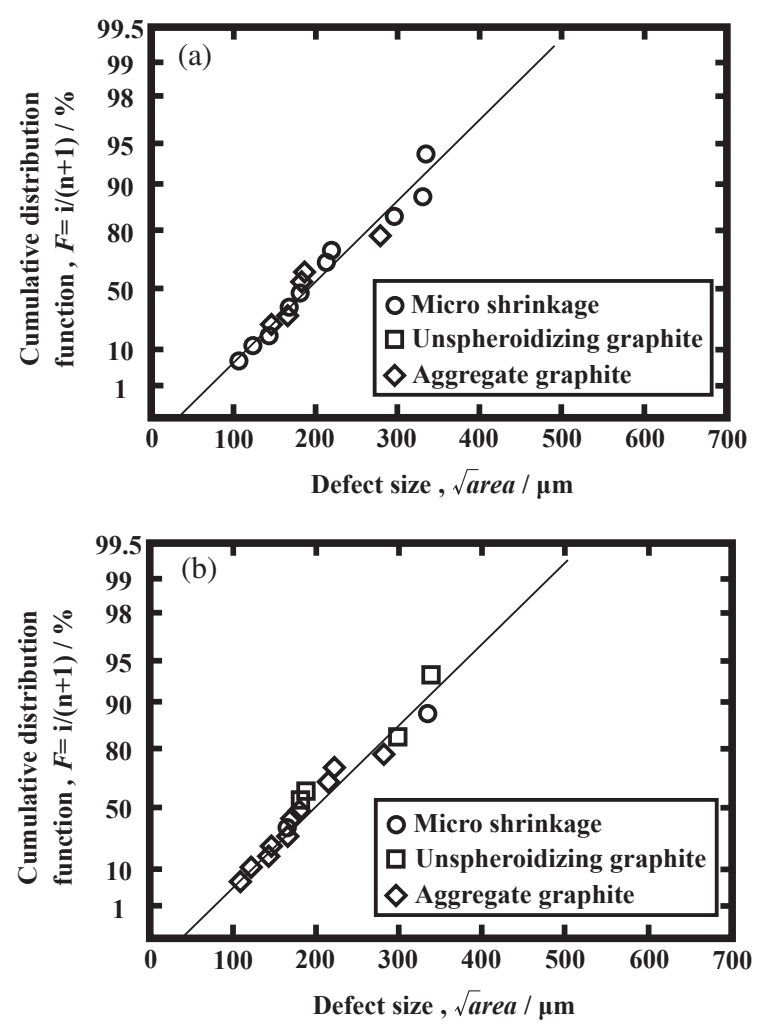

Fig. 10 Gumbel paper which classified fracture origins; (a) PDI3.8, (b) ADI3.8.

dynamically equivalent, it is expected that the fatigue limit is constant depending on the kind of starting point to the extent that the hardness and the defect size are invariant. It is known that in the formula for estimating the fatigue limit of a material with micro defects, the fatigue limit depends on the defect size and the hardness of the matrix. ${ }^{9)}$ Also, in the specimens used in this study, the estimated fatigue limit agreed well with the experiment. In addition, from the fact that appreciable differences are not seen in the defect size between ADI and PDI materials in Fig. 9, it is considered that the difference in fatigue limit between ADI and PDI materials as shown in Fig. 3 is due to the difference in the hardness of the matrix. From the number of graphite as shown in Fig. 1, it should be expected that, when the number of graphite is large and a lot of graphite nodules gather, they become a large defect and the defect size of an aggregate graphite nodule increases. However, actually, the defect size is approximately constant independently of the number of graphite, and this agrees well with the results on fatigue limit. In addition, Fig. 10(a), (b) separately plots the kinds of fracture origins on the gumbel paper as used for finding the mean defect size. In the fracture origins of both materials, both large- and small-sized defects are uniformly distributed, and there is no clear correlation between the type of fracture origin and the defect size. Therefore, it can be inferred that all fracture origins are dynamically equivalent and the maximum sized defect in the critical cross section of the specimen becomes the fracture origin.

It is clear from the above results that, when the carbon content is changed, the number of graphite of spheroidal graphite cast iron changes, and as the graphite nodule spacing 
decreases, an aggregate graphite group becomes a large defect and initiates a fatigue crack.

\section{Conclusions}

By changing the carbon content to produce thick spheroidal graphite cast iron with different number of graphite, and performing the rotating bending fatigue test, the following became clear.

(1) A clear difference was not seen in the fatigue limit when the number of graphite was changed.

(2) Three kinds of fracture origins - micro shrinkage, unspheroidizing graphite nodules, and aggregate graphite nodules - were confirmed.

(3) There is no clear correlation between the type of fracture origin and the defect size, and all fracture origin acts as a dynamically equivalent defect.

(4) When the number of graphite increased, the graphite nodule spacing decreased, and many fracture origins were aggregate graphite nodules. In particular, in the specimen with a large number of graphite, the graphite nodules are very close to each other and accordingly graphite nodules of $80 \%$ or more could be aggregate graphite nodules.

\section{REFERENCES}

1) M. Uemura and M. Sunagawa: Trans. JSME (in Japanese) 24 (1958) $459-465$.

2) T. Shiota and S. Komatsu: J. JFS 54 (1982) 434-439.

3) T. Kanno, I. Kang, Y. Fukuda, T. Mizuki and S. Kiguchi: J. JFS 77 (2005) 9-17.

4) H. Kage: J. JFS 82 (2010) 777-779.

5) H. Kage: Sokeizai 51 No. 5 (2010) 10-14.

6) JIS G 5502: Spheroidal Graphite Iron Castings, (2007).

7) JIS Z 2274: Method of Rotating Bending Fatigue Testing of Metals, (1978).

8) JSMS-SD-6-02: Standard Evaluation Method of Fatigue Reliability for Metallic Materials, Standard Regression Method of S-N Curves, (2002).

9) Y. Murakami: Metal Fatigue, Effects of Small Defects and Nonmetallic Inclusions, (Yokendo, 1993) p. 43. 